\title{
Validation Thin Layer Chromatography for the Determination of Acetaminophen in Tablets and Comparison with a Pharmacopeial Method
}

\author{
Alina Pyka, Marika Budzisz, and Małgorzata Dołowy \\ Department of Analytical Chemistry, Faculty of Pharmacy, Medical University of Silesia, PL-4 Jagiellonska Street, \\ 41-200 Sosnowiec, Poland \\ Correspondence should be addressed to Alina Pyka; apyka@sum.edu.pl
}

Received 17 April 2013; Accepted 19 July 2013

Academic Editor: Deliang Zhou

Copyright (C) 2013 Alina Pyka et al. This is an open access article distributed under the Creative Commons Attribution License, which permits unrestricted use, distribution, and reproduction in any medium, provided the original work is properly cited.

Adsorption thin layer chromatography (NP-TLC) with densitometry has been established for the identification and the quantification of acetaminophen in three leading commercial products of pharmaceutical tablets coded as brand: P1 (Product no. 1), P2 (Product no. 2), and P3 (Product no. 3). Applied chromatographic conditions have separated acetaminophen from its related substances, namely, 4 -aminophenol and and $4^{\prime}$-chloroacetanilide. UV densitometry was performed in absorbance mode at $248 \mathrm{~nm}$. The presented method was validated by specificity, range, linearity, accuracy, precision, detection limit, quantitative limit, and robustness. The TLC-densitometric method was also compared with a pharmacopeial UV-spectrophotometric method for the assay of acetaminophen, and the results confirmed statistically that the NP-TLC-densitometric method can be used as a substitute method. It could be said that the validated NP-TLC-densitometric method is suitable for the routine analysis of acetaminophen in quantity control laboratories.

\section{Introduction}

Acetaminophen (paracetamol) has pharmacological and pharmaceutical significance. It is a nonsteroidal anti-inflammatory drug and is used for the reduction of pain and fever. Acetaminophen is commonly used for the relief of headaches and other minor aches and is a major ingredient in numerous cold and flu remedies.

Acetaminophen was quantitatively determined in different biological fluids, namely, plasma [1-6], urine [7-12], serum [11, 13], and tissue [14]. Moreover, acetaminophen was also determined in different pharmaceutical preparations in single and in combined dosage forms [15-30].

As was reported in the literature, several methods like liquid chromatography $[1,4,5,21]$, high performance liquid chromatography $[3,8,10,12,17,18]$, reversed-phase sequential injection chromatography (SIC) [20], spectrophotometric $[7,9,13,16]$, spectrophotometric with spectrodensitometric [22], spectrofluorimetric [15], capillary electrophoresis [11, 19], colorimetric [2, 6], chronoamperometric [14], thin layer chromatography with spectrophotometric [23], and thin layer chromatography with a fluorescence plate reader [24], and thin layer chromatography (HPTLC) with a densitometry were successfully applied in qualitative and quantitative acetaminophen analysis [25-30]. Generally, HPLC and UVspectrophotometric methods have been reported in the United States and Polish Pharmacopeias for the analysis of acetaminophen in pharmaceutical preparations $[31,32]$.

Dimitrovska et al. [23] described the conditions for the determination of propyphenazone, acetaminophen, caffeine, and codeine phosphate in commercial tablet dosage with preparative thin layer chromatography. The separation of propyphenazone, acetaminophen, and caffeine was performed by use of a mobile phase chloroform + acetone + ammonium hydroxide (25\%) in volume rations $8: 2: 0.1$. Codeine phosphate was separated from the other components with chloroform + ethanol in volume ration $8: 2$, as a mobile phase. UV-spectrophotometric determinations of propyphenazone, acetaminophen, caffeine, and codeine after their separation on thin layer and elution from the adsorbent were performed. Tavallali et al. [24] developed a method to determine caffeine and acetaminophen concentrations in 
pharmaceutical formulations using TLC with a fluorescence plate reader. Separation of acetaminophen and caffeine was performed using the mobile phase $n$-hexane + ethyl acetate + ethanol $(2.5: 1.5: 0.4, \mathrm{v} / \mathrm{v})$.

Many papers described the determination of acetaminophen in single and in combined tablet dosage forms using TLC with densitometry [24-30]. However, authors did not separate the related substances (4-aminophenol and $4^{\prime}$-choroacetanilide) to acetaminophen. This fact indicates that the previous TLC-densitometric methods presented in cited previous papers were not validated in term of specificity accordance to validation guidelines $[33,34]$. Ferenczi-Fodor and coworkers described in their papers that besides the typical validation characteristics such as accuracy, precision, repeatability, specificity, detection limit, quantification limit, linearity, and range, in the case of liquid chromatography the evaluation of robustness should be considered $[34,35]$. It is a critical parameter having significant effect for final results of chromatographic analysis. It was stated that when this parameter is not constant, the analytical process should be improved $[34,35]$. According to $\mathrm{ICH}$ guideline, the robustness test includes the influence of the variations of the following parameters like variations of $\mathrm{pH}$ in a mobile phase, variations in mobile phase composition, different column and temperature on final results of liquid chromatographic analysis [33].

Presented work is a continuation of our previous TLC acetaminophen study. In earlier paper we described the preliminary investigations for the analysis of acetaminophen by TLC with densitometry including the choice of the optimal chromatographic conditions enabled to complete separation of examined acetaminophen from its related substances (4aminophenol and $4^{\prime}$-choroacetanilide) such as silica gel $60 \mathrm{~F}_{254}$ plates and a mixture of chloroform + acetone + ammonia (25\%) in volume compositions $8: 2: 0.1$ as a mobile phase [36].

The aims of this work were to

(i) elaborate the conditions for quantitative determination of acetaminophen in tablets by a TLCdensitometric method with regard to obligatory validation presented in validation guidelines and in Ferenczi-Fodor and also Nagy-Turák reports including robustness test [33-35];

(ii) apply the spectrophotometric method recommended by Polish Pharmacopoeia to the quantitative determination of acetaminophen in tablets [31];

(iii) compare the results of quantitative determination of acetaminophen in tablets obtained by TLCdensitometric and spectrophotometric methods.

Based on the obtained results the usefulness of the validated TLC-densitometric method for quantitative analysis of acetaminophen in combined dosage form in comparison to spectrophotometric method (recommended by Polish Pharmacopoeia) was estimated. Moreover, the use of the changes of the following chromatographic conditions such as sorbent type, the chamber type, extraction time, the temperature of plate activation, the distance of development, the wavelength, and the analyst as the new factors in robustness test of TLCdensitometric method was discussed.

\section{Materials and Methods}

2.1. Apparatus. Densitometer: Camag (Muttenz, Switzerland) equipped with TLC Scanner.

Spectrophotometer: Specord 205 (Analytik Jena, Germany).

IKA Ultra-Turrax Tube Drive Workstation with BMT-20$S$ Tube for grinding with balls of stainless steel.

NP-TLC plates: $10 \times 20 \mathrm{~cm}$ glass plates precoated with $0.20 \mathrm{~mm}$ layers of silica gel $60 \mathrm{~F}_{254}$ (E.Merck, \#1.05570); $20 \times$ $20 \mathrm{~cm}$ aluminium plates precoated with $0.20 \mathrm{~mm}$ layers of silica gel $60 \mathrm{~F}_{254}$ (E.Merck, \#1.05554).

The $5 \mu \mathrm{L}$ Camag micropipettes were used to apply the solutions to the plates.

Chromatographic chambers: twin-trough chamber for $20 \times 20 \mathrm{~cm}$ plates $(\# 0.222 .5255$, Camag, Muttenz, Switzerland) and twin-trough chamber for $20 \times 10 \mathrm{~cm}$ plates (\#0.222.5221, Camag, Muttenz, Switzerland).

2.2. Chemicals. Acetaminophen (Sigma-Aldrich, St. Louis, MO, USA), testing and handling conforms to United States Pharmacopeia, 4-aminophenol (>99\%, Sigma-Aldrich, St. Louis, MO, USA), and $4^{\prime}$-chloroacetanilide (>98\%, SigmaAldrich, St. Louis, MO, USA), were used as standards. All chemicals and reagents used for TLC were analytical grade and were purchased from POCh, Gliwice, Poland.

2.3. Pharmaceutical Preparation. Pharmaceutical preparations of three different pharmaceutical manufactures containing $500 \mathrm{mg}$ of acetaminophen per tablet (Product 1) and also $500 \mathrm{mg}$ per dragged tablet (Product 2 and Product 3 ) were investigated.

2.4. Preparation Sample of Tablets. Ten tablets were ground for $20 \mathrm{~min}$ with a speed equal to $4000 \mathrm{rpm}$ using an IKA Ultra-Turrax Tube Drive Workstation with a BMT20-S tube for grinding with balls of stainless steel. The obtained powders of acetaminophen tablets (equivalent to $25 \mathrm{mg}$ acetaminophen by weighing the powder to an accuracy of $0.1 \mathrm{mg}$ ) were shaken with ethanol $(99.8 \%, 10 \mathrm{~mL})$ for $5 \mathrm{~min}$ with a speed equal to $4000 \mathrm{rpm}$. After shaking, the solutions were filtered through a medium-density filter to volumetric flasks $(25 \mathrm{~mL})$ and replenished using ethanol $(99.8 \%)$ to demanded volume. From these solutions, were next prepared the solutions with about the concentrations of active substances (acetaminophen) equal to $0.30 \mathrm{mg} \cdot \mathrm{mL}^{-1}, 0.20 \mathrm{mg} \cdot \mathrm{mL}^{-1}$, and $0.10 \mathrm{mg} \cdot \mathrm{mL}^{-1}$. These solutions $(5 \mu \mathrm{L})$ were used for the TLC-densitometric analysis and for quantitative determination of acetaminophen in certain pharmaceutical preparations. The equivalent of $100 \mathrm{mg}$ acetaminophen by weight of the powder was also used for UV-spectrophotometric analysis.

2.5. Preparation of Standard Solution of Acetaminophen and Its Related Substances. Standard solutions of acetaminophen 
and standard solutions of 4 -aminophenol and $4^{\prime}$-chloroacetanilide were prepared by dissolving the solutes in ethanol (99.8\%).

2.6. Thin Layer Chromatography. The plates were prewashed with methanol and dried for $24 \mathrm{~h}$ at room temperature. Before use the plates used in NP-TLC were activated at $120^{\circ} \mathrm{C}$ for $10 \mathrm{~min}$. TLC-densitometric method for determination of acetaminophen was performed on aluminium plates precoated with $0.20 \mathrm{~mm}$ layers of silica gel $60 \mathrm{~F}_{254}$ (E.Merck, $\# 1.05570$ ). Additionally, $20 \times 20 \mathrm{~cm}$ aluminum plates precoated with $0.20 \mathrm{~mm}$ layers of silica gel $60 \mathrm{~F}_{254}$ (E.Merck, \#1.05554) were used to test robustness. The robustness of an analytical procedure is a measure of its capacity to remain unaffected by small but deliberate variations in method parameters.

The solutions of acetaminophen samples and acetaminophen standards $(5 \mu \mathrm{L})$ were spotted manually on the chromatographic plates.

The mixture of chloroform + acetone + ammonia (25\%) in volume compositions $8: 2: 0.1$ was used as mobile phase. Of the mobile phase, $50 \mathrm{~mL}$ was used in all cases. After saturation of the twin-trough chamber $(20 \mathrm{~cm} \times 20 \mathrm{~cm})$ with the mobilephase vapor for $15 \mathrm{~min}$, the plates were developed vertically at room temperature $\left(20^{\circ} \mathrm{C}\right)$ to a distance of $7.5 \mathrm{~cm}$. The plates were then dried for $20 \mathrm{~h}$ at room temperature $\left(20^{\circ} \mathrm{C}\right)$ in a fume cupboard.

Additionally, a twin-trough chamber of $20 \times 10 \mathrm{~cm}$ (\#0.222.5221, Camag) was used to test robustness.

\subsection{Densitometric and Spectrodensitometric Investigations.} Densitometric and spectrodensitometric investigations were done using a TLC Scanner 3 operated in the absorbance mode. The radiation source was a deuterium lamp emitting a continuous UV spectrum between 190 and $450 \mathrm{~nm}$. Densitometric scanning was then performed at multiwavelength in the range of 200 to $400 \mathrm{~nm}$, at wavelength intervals of $50 \mathrm{~nm}$ at each step. Finally, densitometric scanning, for quantitative determination of acetaminophen, was then performed at absorption maximum of acetaminophen equal to $248 \mathrm{~nm}$. The chromatographic bands obtained on the densitograms were also investigated by spectrodensitometric analysis under the following conditions. The slit dimensions were $10.00 \times 0.40 \mathrm{~mm}$, Macro; the optimal optical system was light; the scanning speeds were $20 \mathrm{~mm} \cdot \mathrm{s}^{-1}$ and $20 \mathrm{~nm} \cdot \mathrm{s}^{-1}$, respectively, for densitometric and spectrodensitometric analysis; the data resolution was $100 \mu \mathrm{m} \cdot$ step $^{-1}$ and $1 \mathrm{~nm} \cdot$ step $^{-1}$, respectively, for densitometric and spectrodensitometric analysis; the measurement type was remission; and the measurement mode was absorption.

2.8. Validation of the TLC Method. The proposed method was validated by specificity, range, linearity, accuracy, precision, detection limit, quantitative limit, and robustness according to the ICH guidelines [33] and according to the guidelines described by Ferenczi-Fodor et al. [34].
2.8.1. Specificity. The specificity of the method was checked by chromatography of working standard (acetaminophen) and related substances (4-aminophenol and $4^{\prime}$-chloroacetanilide) and sample solution of acetaminophen extracted from tablets.

2.8.2. Linearity of Detector Response and Range. The linearity of the TLC method was evaluated by analysis of nine standard solutions of acetaminophen of concentrations $0.08,0.10,0.12$, $0.15,0.20,0.25,0.30,0.35$, and $0.40 \mathrm{mg} \cdot \mathrm{mL}^{-1}$. The solutions $(5 \mu \mathrm{L})$ were applied to the same plate. The plates were developed using above-mentioned mobile phases (in thin layer chromatography section) and scanned. The experiments were performed in six different analyses.

2.8.3. Accuracy. The accuracy of the TLC method was evaluated by measurement of recovery. Known amounts of acetaminophen standards in the low, medium, and high levels of the calibration plot were added to powdered tablets of known acetaminophen content, and the tablets were extracted and analyzed under the optimized conditions. The experiments were performed in six different analyses.

2.8.4. Precision. Repeatability (intraday precision) of the method was determined by analysis of three replicates of three sample solutions (ethanol extracts of acetaminophen) of different concentrations $\left(0.10,0.20\right.$, and $\left.0.30 \mathrm{mg} \cdot \mathrm{mL}^{-1}\right)$ under the same operating conditions over a short interval of time (the same day). Intermediate (interday) precision was obtained for three sample solutions of different concentrations $\left(0.10,0.20\right.$, and $\left.0.30 \mathrm{mg} \cdot \mathrm{mL}^{-1}\right)$ by an analyst who performed the analysis over a period of two weeks. To determine the precision of the procedure, the concentrations were prepared independently and experiments were performed in three different analyses. The precision was evaluated as the relative standard deviation (coefficient of variation, CV [\%]).

2.8.5. Detection Limit and Quantitative Limit Based on the Calibration Curve. A specific calibration curve was studied using samples containing acetaminophen in the range of the detection limit, namely, $0.125,0.250$, and $0.400 \mu \mathrm{g} \cdot \mathrm{spot}^{-1}$. The experiments were performed in six different analyses.

The detection limit (DL) was calculated as

$$
\mathrm{DL}=\frac{3.3 \sigma}{S} \text {. }
$$

The quantitative limit (QL) was calculated as

$$
\mathrm{QL}=\frac{10 \sigma}{S},
$$

where $\sigma$ is the standard deviation of the response and $S$ is the slope of the calibration curve.

2.8.6. Robustness. The robustness of the method was tested according to guidelines described in the papers by NagyTurák and Ferenczi-Fodor et al. [34, 35, 37]. The robustness of the method was checked by spotting sample solution 
TABLE 1: The factors and their levels investigated in robustness test.

\begin{tabular}{|c|c|c|c|c|}
\hline \multirow{2}{*}{ Symbol } & \multirow{2}{*}{ Factors } & \multirow{2}{*}{ Method condition } & \multicolumn{2}{|c|}{ Levels } \\
\hline & & & + & - \\
\hline$X_{1}$ & $\begin{array}{l}\text { Sorbent type } \\
(\text { Merck, \#) }\end{array}$ & $\begin{array}{c}\text { Al sheet } \\
(1.05554)\end{array}$ & $\begin{array}{l}\text { Al sheet } \\
(1.05554)\end{array}$ & $\begin{array}{l}\text { Al sheet } \\
(1.05570)\end{array}$ \\
\hline$X_{2}$ & Chamber type & $\begin{array}{l}\text { Twin trough, } \\
20 \mathrm{~cm} \times 20 \mathrm{~cm}\end{array}$ & $\begin{array}{l}\text { Twin trough, } \\
20 \mathrm{~cm} \times 20 \mathrm{~cm}\end{array}$ & $\begin{array}{l}\text { Twin trough, } \\
20 \mathrm{~cm} \times 10 \mathrm{~cm}\end{array}$ \\
\hline$X_{3}$ & Temperature of plate activation $\left({ }^{\circ} \mathrm{C}\right)$ & 120 & 130 & 110 \\
\hline$X_{4}$ & Extraction time $(\mathrm{min})$ & 5 & 6 & 4 \\
\hline$X_{5}$ & Distance of development $(\mathrm{cm})$ & 7.5 & 8.0 & 7.0 \\
\hline$X_{6}$ & Wavelength $(\mathrm{nm})$ & 248 & 250 & 246 \\
\hline$X_{7}$ & Analyst & $\mathrm{A}$ & A & $\mathrm{B}$ \\
\hline
\end{tabular}

TABLE 2: Experimental design matrix $\left(2^{3}\right)$ for robustness test.

\begin{tabular}{|c|c|c|c|c|c|c|c|c|c|c|}
\hline \multirow[t]{2}{*}{ Experiment no. } & \multirow[t]{2}{*}{$X_{1}$} & \multirow[t]{2}{*}{$X_{2}$} & \multirow[t]{2}{*}{$X_{3}$} & \multirow[t]{2}{*}{$X_{4}$} & \multirow[t]{2}{*}{$X_{5}$} & \multirow[t]{2}{*}{$X_{6}$} & \multirow[t]{2}{*}{$X_{7}$} & \multicolumn{3}{|c|}{$\begin{array}{l}\text { Acetaminophen content }\left(y_{i}\right) \\
{\left[\mathrm{mg} \cdot \text { tablet }^{-1}\right] \text { in tablets }}\end{array}$} \\
\hline & & & & & & & & P1 & P2 & P3 \\
\hline 1 & + & + & + & + & + & + & + & 499.0 & 494.5 & 501.2 \\
\hline 2 & + & + & - & + & - & - & - & 454.2 & 451.6 & 459.8 \\
\hline 3 & + & - & + & - & - & + & - & 496.4 & 494.1 & 496.7 \\
\hline 4 & + & - & - & - & + & - & + & 485.1 & 481.4 & 488.2 \\
\hline 5 & - & + & + & - & + & - & - & 501.1 & 501.3 & 503.4 \\
\hline 6 & - & + & - & - & - & + & + & 495.8 & 491.5 & 492.5 \\
\hline 7 & - & - & + & + & - & - & + & 478.0 & 477.9 & 485.6 \\
\hline 8 & - & - & - & + & + & + & - & 485.9 & 477.2 & 483.5 \\
\hline \multicolumn{11}{|l|}{ Effect of the drug } \\
\hline P1 & -6.525 & 1.175 & 13.375 & -15.325 & 11.675 & 14.675 & 5.075 & & & \\
\hline $\mathrm{P} 2$ & -6.579 & 2.078 & 16.521 & -16.777 & 9.804 & 11.297 & 5.278 & & & \\
\hline P3 & -4.775 & 0.725 & 15.725 & -12.675 & 10.425 & 9.225 & 6.025 & & & \\
\hline
\end{tabular}

${ }^{\mathrm{a}}$ Product 1 (P1), Product 2 (P2), Product 3 (P3).

$\left(1.00 \mu \mathrm{g} \cdot \mathrm{spot}^{-1}\right)$ on the plate and developing the plate after altering the conditions (Table 1). The conditions changed were the sorbent type, the chamber type, extraction time, the temperature of plate activation, the distance of development, the wavelength, and the analyst. The method conditions and the selected factors with the values of their $(+)$ and $(-)$ levels are summarized in Table 1. A high level is represented by "+" and a low level by "-". The main effects of seven factors were tested on two levels in eight experiments [35, 37]. The levels of factors investigated and the experimental design matrix $\left(2^{3}\right)$ are shown in Tables 1 and 2, respectively. The ways of calculation of the effects $(E)$ characterizing the particular individual factors and rank probabilities [38] were early presented [35, 37, 39-43].

2.9. Comparison with Pharmacopeial Method. When developing a new analytical method, it is desirable to compare the results from the new method with those from an accepted method. Sample solutions were analyzed by TLC-densitometric method and by the method recommended in the Polish Pharmacopeia, namely, the UVspectrophotometric method [31]. The equivalent of $100 \mathrm{mg}$ of acetaminophen with $15 \mathrm{~mL}$ of hydrochloric acid $(3.6 \mathrm{~g} / \mathrm{L})$ was shaken for 30 minutes, and then sufficient hydrochloric acid $(3.6 \mathrm{~g} / \mathrm{L})$ was added to produce $100 \mathrm{~mL}$ and filtered. The $1.0 \mathrm{~mL}$ of filtrate was diluted to $100.0 \mathrm{~mL}$ with hydrochloric acid $(3.6 \mathrm{~g} / \mathrm{L})$, and the absorbance of the resulting solution was measured at the maximum of $245 \mathrm{~nm}$ using Specord 205 (Analytik Jena, Germany). The content of acetaminophen was calculated taking 668 as the value of absorbance $(1 \%, 1 \mathrm{~cm})$ at the maximum of $245 \mathrm{~nm}$.

The comparison of TLC-densitometric method with UVspectrophotometric method to determine acetaminophen in pharmaceutical preparations was studied by use of ten independently repeated different analyses.

\section{Results and Discussion}

3.1. Validation of TLC Method. Summarized results of the method of validation are presented in Figures 1, 2, 3, and 4 as well as in Tables 1, 2, and 3.

3.1.1. Specificity. As was reported in Introduction part, our literature survey shows that many papers described 
TABLE 3: Method-validation data for the quantitative determination of acetaminophen by NP-TLC with densitometry ${ }^{\mathrm{a}}$.

\begin{tabular}{|c|c|c|c|}
\hline Method characteristic & \multicolumn{3}{|c|}{ Results } \\
\hline Specificity & \multicolumn{3}{|c|}{ Specific } \\
\hline Range $\left[\mu \mathrm{g} \cdot \operatorname{spot}^{-1}\right]$ & \multicolumn{3}{|c|}{$0.40 \div 1.75$} \\
\hline Linearity $\left[\mu \mathrm{g} \cdot \operatorname{spot}^{-1}\right]$ & \multirow{2}{*}{\multicolumn{3}{|c|}{$\begin{aligned} A & =2444.4( \pm 68.3)+7249.8( \pm 63.7) \cdot x \\
n=8 ; r & =0.9998 ; s=83.0 ; F=12952 ; P<0.0001\end{aligned}$}} \\
\hline Linearity [ $\mu \mathrm{g} \cdot \mathrm{spot}]$ & & & \\
\hline Detection limit $(\mathrm{DL})\left[\mu \mathrm{g} \cdot \mathrm{spot}^{-1}\right]$ & \multicolumn{3}{|c|}{0.09} \\
\hline \multirow[t]{3}{*}{ Quantitation limit $(\mathrm{QL})\left[\mu \mathrm{g} \cdot \mathrm{spot}^{-1}\right]$} & \multicolumn{3}{|c|}{0.27} \\
\hline & \multicolumn{3}{|c|}{ For tablets } \\
\hline & Product 1 & Product 2 & Product 3 \\
\hline \multicolumn{4}{|l|}{ Accuracy } \\
\hline For $50 \%$ acetaminophen added $(n=6)$ & $R=100.72 \% ; \mathrm{CV}=1.13 \%$ & $R=99.69 \% ; \mathrm{CV}=0.91 \%$ & $R=101.34 \% ; \mathrm{CV}=1.29 \%$ \\
\hline For $100 \%$ acetaminophen added $(n=6)$ & $R=100.58 \% ; C V=1.21 \%$ & $R=99.63 \% ; \mathrm{CV}=0.92 \%$ & $R=102.34 \% ; C V=1.33 \%$ \\
\hline For $150 \%$ acetaminophen added $(n=6)$ & $R=101.23 \% ; C V=0.86 \%$ & $R=99.27 \% ; \mathrm{CV}=1.12 \%$ & $R=100.87 \% ; C V=1.08 \%$ \\
\hline \multicolumn{4}{|l|}{ Precision $(\mathrm{CV},[\%])$} \\
\hline \multicolumn{4}{|l|}{ Repeatability } \\
\hline For $0.50 \mu \mathrm{g} \cdot \operatorname{spot}^{-1}(n=3)$ & 0.57 & 0.85 & 0.99 \\
\hline For $1.00 \mu \mathrm{g} \cdot \operatorname{spot}^{-1}(n=3)$ & 0.66 & 0.76 & 0.78 \\
\hline For $1.50 \mu \mathrm{g} \cdot \operatorname{spot}^{-1}(n=3)$ & 1.00 & 0.73 & 1.11 \\
\hline \multicolumn{4}{|l|}{ Intermediate } \\
\hline For $0.50 \mu \mathrm{g} \cdot \operatorname{spot}^{-1}(n=3)$ & 0.85 & 1.41 & 1.11 \\
\hline For $1.00 \mu \mathrm{g} \cdot \operatorname{spot}^{-1}(n=3)$ & 1.20 & 1.57 & 0.99 \\
\hline For $1.50 \mu \mathrm{g} \cdot \operatorname{spot}^{-1}(n=3)$ & 1.13 & 1.36 & 1.56 \\
\hline Robustness (CV, [\%]) & Robust & Robust & Robust \\
\hline
\end{tabular}

${ }^{\mathrm{a}} A$ : peak area $[\mathrm{AU}], x$ : amount $\left[\mu \mathrm{g} \cdot \operatorname{spot}^{-1}\right]$ of drug analyzed, $r$ : correlation coefficient, $R$ : recovery [\%], CV: coefficient of variation [\%].

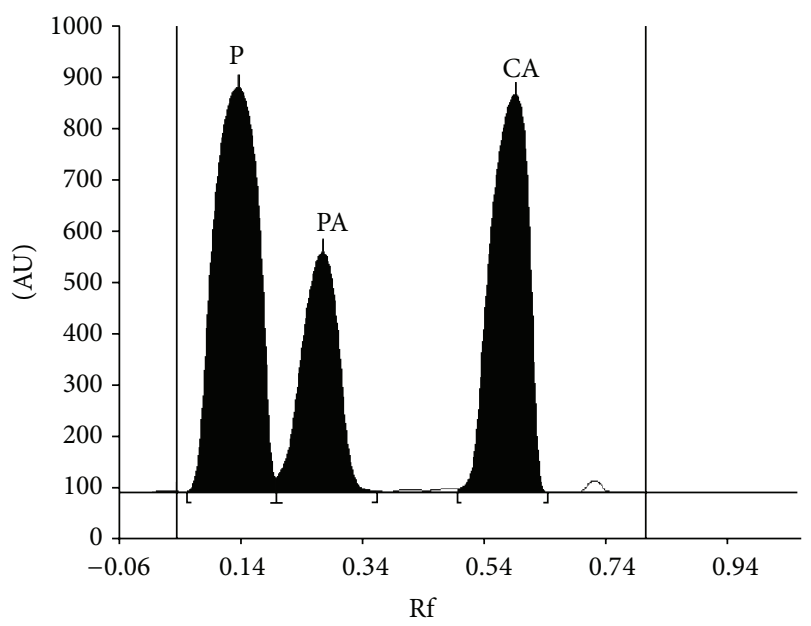

FIGURE 1: Densitogram obtained from acetaminophen standard (P) spiked with related substances, namely, p-aminophenol (PA) and $4^{\prime}$ chloroacetanilide (CA).

the determination of acetaminophen in commercial products with the use of TLC and TLC-densitometry [24-30]. Various chromatographic conditions such as mobile phase composition and the kind of TLC plates were studied to obtain satisfactory results of acetaminophen qualitative and quantitative analysis. Based on the literature reports, our

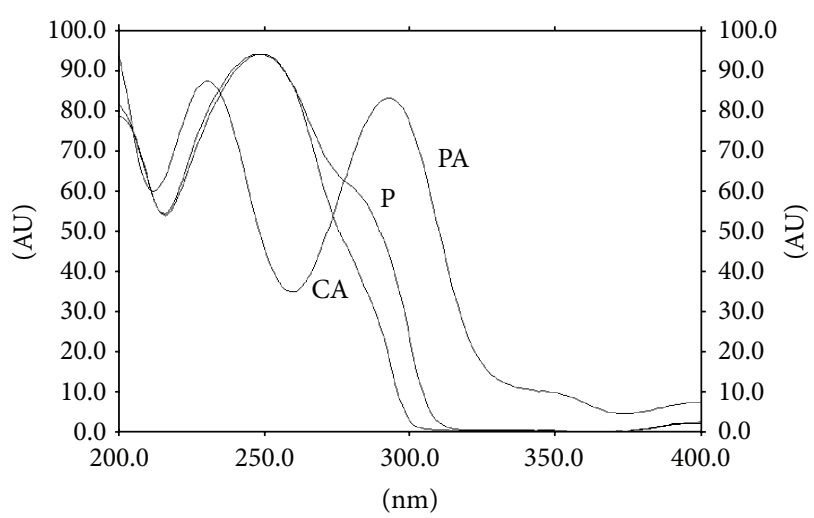

FIgURE 2: Spectrodensitograms of acetaminophen standard (P), paminophenol (PA), and $4^{\prime}$-chloroacetanilide (CA).

TLC-densitometry of acetaminophen was performed on aluminium plates precoated with silica gel $60 \mathrm{~F}_{254}$ (recommended in literature for acetaminophen TLC analysis). In order to choose the optimal mobile phase which allows separating acetaminophen and its related substances (4aminophenol and $4^{\prime}$-chloroacetanilide) from commercial product, different compositions and ratios of ammonia, toluene, ethyl acetate, chloroform, cyclohexane, methanol, nhexane, acetone, and glacial acetic acid were examined. Of all 


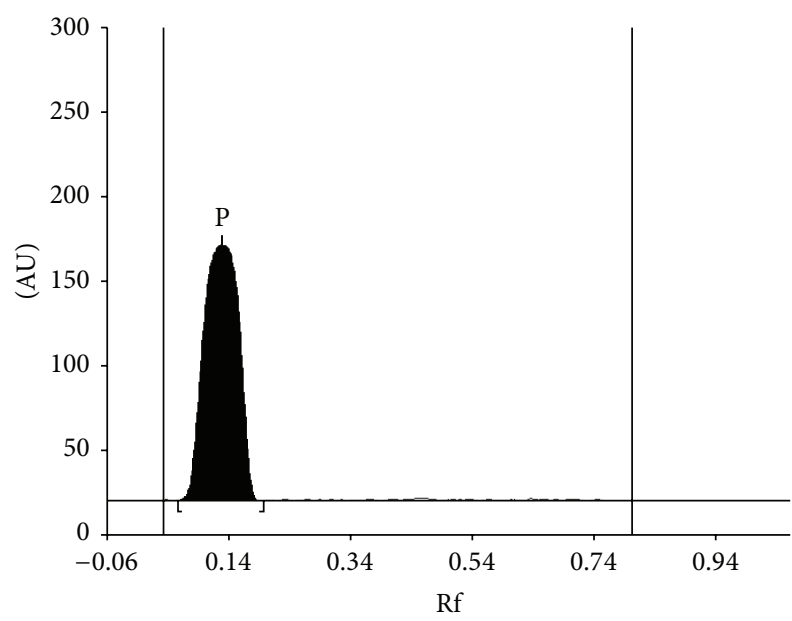

FIGURE 3: Densitogram of acetaminophen (P) coming from Product 2 sample.

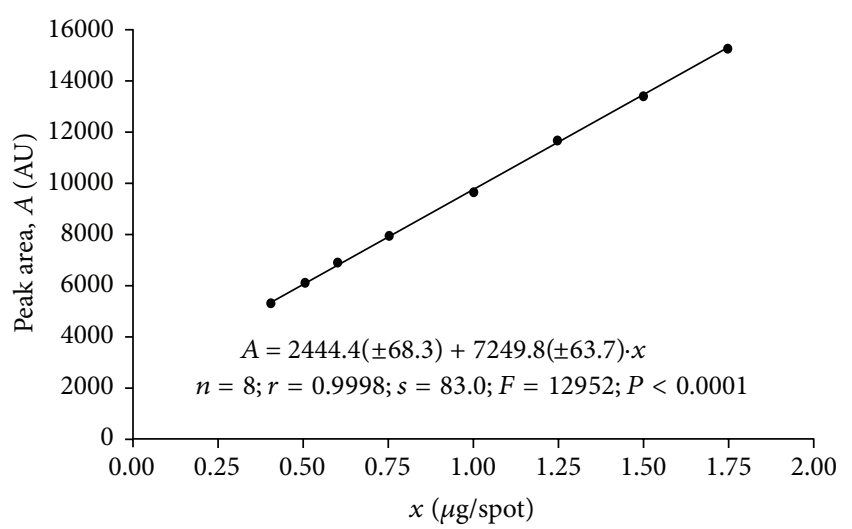

(a)

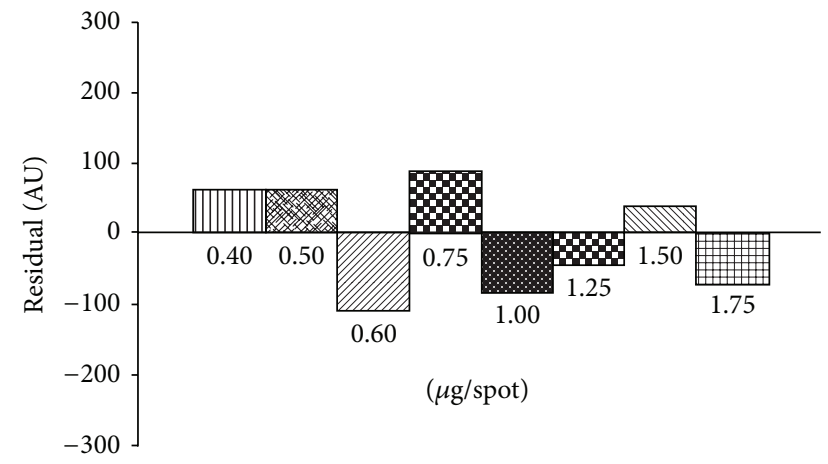

(b)

FIGURE 4: Calibration plot (a) and plot of residuals (b) for acetaminophen in the linear working range.

mobile phases used in experiment, the mixture of chloroform + acetone + ammonia (25\%) in volume compositions $8: 2: 0.1$ as mobile phase resulted in compact bands and sharp and symmetric peaks of acetaminophen $(\mathrm{P})$, related substances, namely, p-aminophenol (PA) and $4^{\prime}$-chloroacetanilide (CA). The mixture of chloroform + acetone + ammonia $(25 \%)(8: 2: 0.1, \mathrm{v} / \mathrm{v} / \mathrm{v})$ used as mobile phase resulted in optimum migration acetaminophen $\left(R_{F(\mathrm{P})}=0.14 \pm 0.01\right)$

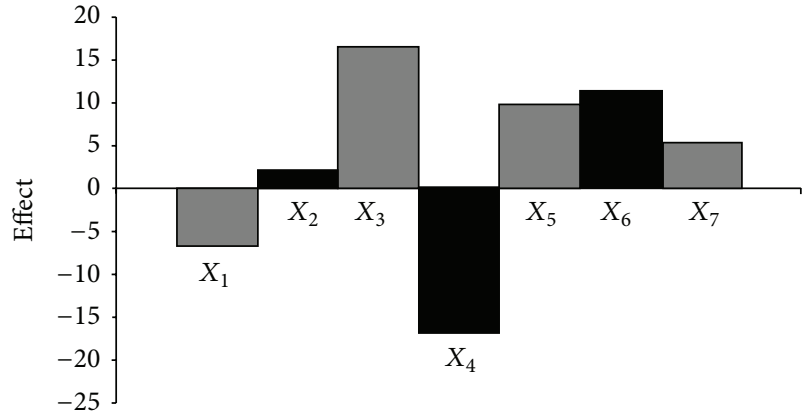

(a)

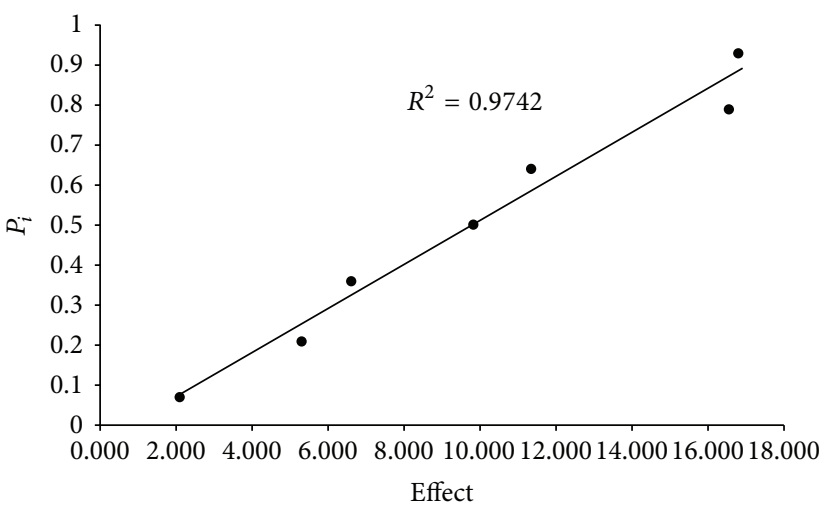

(b)

FIGURE 5: Robustness test: the effects of factors (a) and half-normal probability plot of effects (b) for determination of acetaminophen in Product 2.

and resolution of the drug from its related substances, namely, p-aminophenol $\left(R_{F(\mathrm{PA})}=0.28 \pm 0.02\right)$ and $4^{\prime}$-chloroacetanilide $\left(R_{F(\mathrm{CA})}=0.59 \pm 0.02\right)$ without interference from other components of the formulations matrix. When excess p-aminophenol and $4^{\prime}$-chloroacetanilide were added to the sample solution to check the specificity of the method the chromatogram presented the resolution of the acetaminophen peak from the related substance (p-aminophenol, and $4^{\prime}$-chloroacetanilide) peaks were equal to $R_{S(\mathrm{P} / \mathrm{PA})}=1.25, R_{S(\mathrm{PA} / \mathrm{CA})}=2.76, R_{S(\mathrm{P} / \mathrm{CA})}=3.73$ (Figure 1). Spectrodensitograms of acetaminophen (P), p-aminophenol (PA), and 4'-chloroacetanilide (CA) are presented in Figure 2. The absorption maximum of acetaminophen, p-aminophenol, and $4^{\prime}$-chloroacetanilide are equal to 248,200 , and $249 \mathrm{~nm}$, respectively. Typical densitogram of acetaminophen coming from the extract of Product 2 is presented in Figure 3. The identical densitograms were also obtained for the extract of Products 1 and 3. It was observed that excipients present in the formulation did not interfere with the acetaminophen peak. It was also stated that the analyte was not decomposed during development of the chromatogram and was stabled in solution and on the sorbent at room temperature. These facts indicate that new method is specificity.

3.1.2. Accuracy. The accuracy of the method was evaluated by measurement of recovery (Table 3 ). When known amounts 
of acetaminophen were added to powdered tablets of known acetaminophen, content quantitative recoveries of $99.27 \% \div$ $102.34 \%$ (mean $100.58 \%$ ) were obtained (Table 3 ). The low coefficient of variation values $(\mathrm{CV}<2 \%)$ are indicative of the accuracy of the method.

3.1.3. Calibration and Range. The statistical data shown in Table 3 and Figure 4(a) indicate that linear relationship exists between area of peaks [AU] and concentration of acetaminophen standard $\left[\mu \mathrm{g} \cdot \operatorname{spot}^{-1}\right]$. The plot $(n=8)$ was linear in the range 0.40 to $1.75 \mu \mathrm{g} \cdot \operatorname{spot}^{-1}$ for NP-TLC analysis. The graphs of residuals against the concentration of acetaminophen were also plotted (Figure 4(b)). It was observed that the residuals were distributed both above and below the zero residuals line.

3.1.4. Precision. The precision of the method was studied as repeatability and intermediate of the system at three different concentrations of tablet extractions. The results from these experiments, expressed as the coefficients of variation $(\mathrm{CV}, \%)$ of the, respectively, response factors (a relationship between the peak area and concentration of acetaminophen) are presented in Table 3. Because CV for repeatability and intermediate were $<3 \%$, the method was precise.

3.1.5. Detection Limit (DL) and Quantitative Limit ( $Q L)$ Based on the Calibration Curve. The limits of detection and the limit of quantification were $0.09 \mu \mathrm{g} \cdot \operatorname{spot}^{-1}$ and $0.27 \mu \mathrm{g} \cdot \operatorname{spot}^{-1}$, respectively.

3.1.6. Robustness. The main effects of seven factors were tested on two levels in eight experiments (Tables 1 and 2) for determination of robustness applied NP-TLC method. Table 2 shows the results obtained for acetaminophen content $\left(y_{i}\right)$ in three pharmaceutical preparations coded: P1 (Product 1), P2 (Product 2), and P3 (Product 3). The main effects of the factors calculated from these results $\left(y_{i}\right)$ are also presented in Table 2. These results show that no factor has significant effect on the results. These results were also evaluated by half-normal probability plotting of rank probabilities $\left(p_{i}\right)$ as a function of the absolute values of the main effects [35, 38, 39]. For example, the effects of factors and half-normal probability plot of effects for the determination of acetaminophen in Product 2 are presented in Figure 5. Similarly, results were obtained for determination of acetaminophen in Product 1 and Product 3. The points of all factors lie near the straight line, which indicates that their effect is negligible. Based on the results of the robustness test (Table 2, experimental design matrix $\left(2^{3}\right)$ for robustness), which were determined according to the guidelines described in the papers by Nagy-Turák and Ferenczi-Fodor et al., it was stated that the proposed TLC-densitometric method can be regarded as robust. Moreover, it can be suggested that the modification of robustness test procedure in comparison to the methodology presented by Nagy-Turák and Ferenczi-Fodor et al. [35, 37] and to our previous investigations [39-43] is suitable for robustness study of TLC-densitometric method used in acetaminophen determination in combined pharmaceutical dosage form.

It was stated that besides the robustness factors presented in our previous validation studies concerning TLCdensitometric investigations of different bioactive substances in their pharmaceutical preparations like hydrocortisone, naproxen, tocopherol acetate, and acetylsalicylic acid (e.g., volume of n-hexane, saturation time of the chamber, etc.), the changes of the following chromatographic condition such as sorbent type, the chamber type, extraction time, the temperature of plate activation, the distance of development, the wavelength, and the analyst used in this work can be successfully applied as the new factors in robustness test of TLC-densitometric method which is successfully applied in drug analysis.

3.1.7. Analysis of Acetaminophen in Commercial Tablets. A single spot at an average $R_{F}$ equal 0.14 was observed in the chromatograms obtained from the extract of acetaminophen tablets. There was no interference from excipients present in the tablets. It was also concluded that no degradation of acetaminophen had occurred in the formulation analyzed by the TLC method. In each case, the $R_{F}$ values of acetaminophen standard and acetaminophen from Product 1, Product 2, and Product 3 were equal to $0.14 \div 0.01$ for TLC-densitometric analysis. The identities of acetaminophen standard with acetaminophen from the commercial samples were investigated on the basis of the comparison of their spectra. The very good correspondence between spectrodensitograms was stated. In all cases the absorption maximum $\left(\lambda_{\max }\right)$ is equal to $248 \mathrm{~nm}$. The purities of acetaminophen peaks from the samples of Product 1, Product 2, and Product 3 were also assessed by comparing the spectra obtained from a acetaminophen standard at the peak start, peak apex, and peak end of spot. It was found that $r(S, M)>0.999$ and $r(M, E)>0.999$ for all of the analyses performed by the TLC-densitometric technique. Statistical data concerning the results of quantitative determination of acetaminophen in the ten repeated different analyses of pharmaceutical preparations are presented in Table 4. It was stated that acetaminophen amounts in pharmaceutical preparations determined by TLC-densitometric method are equal to 99.3\%, 99.8\%, and 100.8\%, respectively, for Product 1, Product 2 , and Product 3 in relation to the amounts of acetaminophen declared by the manufacturers.

3.2. Comparison with Pharmacopeial Method. To verify the results obtained by the TLC-densitometric method, comparison was made with a previous report using the Polish Pharmacopeia UV-spectrophotometric method [31]. When compared with the pharmacopeial method recommended for acetaminophen tablets, similar results were obtained for ten repeated different analyses (Table 4). The average assays of acetaminophen were $496.7 \pm 6.4 \mathrm{mg} \cdot$ tablet $^{-1}$ and $495.7 \pm 7.0 \mathrm{mg} \cdot$ tablet $^{-1}$ Product 1, 499.1 $\pm 5.6 \mathrm{mg} \cdot$ tablet $^{-1}$ and $497.5 \pm 4.8 \mathrm{mg} \cdot$ tablet $^{-1}$ Product 2, $503.8 \pm 5.1 \mathrm{mg} \cdot$ tablet $^{-1}$ and $501.4 \pm 7.9 \mathrm{mg} \cdot$ tablet $^{-1}$ Product 3 for TLC-densitometric 
TABLE 4: Acetaminophen assay $\left[\mathrm{mg} \cdot\right.$ tablet $\left.^{-1}\right]$ obtained from ten repeated different analyses by TLC-densitometric and UV-spectrodensitometric methods for tablets of three different pharmaceutical manufactures.

\begin{tabular}{|c|c|c|c|c|c|c|}
\hline \multirow[b]{2}{*}{ No. } & \multicolumn{2}{|c|}{ Product 1} & \multicolumn{2}{|c|}{ Product 2} & \multicolumn{2}{|c|}{ Product 3} \\
\hline & $\begin{array}{l}\text { Assay } \\
\text { by TLC- } \\
\text { densitometric } \\
\text { method }\end{array}$ & $\begin{array}{c}\text { Assay } \\
\text { by UV- } \\
\text { spectrophotometric } \\
\text { method }\end{array}$ & $\begin{array}{c}\text { Assay } \\
\text { by TLC- } \\
\text { densitometric } \\
\text { method } \\
\end{array}$ & $\begin{array}{c}\text { Assay } \\
\text { by UV- } \\
\text { spectrophotometric } \\
\text { method }\end{array}$ & $\begin{array}{c}\text { Assay } \\
\text { by TLC- } \\
\text { densitometric } \\
\text { method } \\
\end{array}$ & $\begin{array}{c}\text { Assay } \\
\text { by UV- } \\
\text { spectrophotometric } \\
\text { method }\end{array}$ \\
\hline 1 & 500.3 & 502.3 & 509.0 & 504.5 & 502.4 & 505.7 \\
\hline 2 & 503.5 & 491.3 & 488.1 & 497.5 & 496.8 & 489.8 \\
\hline 3 & 488.3 & 486.5 & 499.6 & 494.7 & 509.6 & 511.2 \\
\hline 4 & 495.2 & 494.4 & 504.4 & 498.6 & 497.8 & 492.3 \\
\hline 5 & 500.5 & 493.5 & 494.3 & 503.6 & 502.7 & 508.9 \\
\hline 6 & 491.8 & 490.6 & 499.6 & 489.9 & 505.8 & 506.7 \\
\hline 7 & 489.1 & 494.5 & 499.2 & 497.3 & 497.6 & 491.2 \\
\hline 8 & 504.2 & 506.2 & 501.5 & 501.9 & 509.8 & 505.9 \\
\hline 9 & 503.1 & 506.9 & 496.9 & 492.9 & 506.7 & 497.9 \\
\hline 10 & 491.2 & 490.8 & 498.8 & 493.9 & 508.9 & 504.6 \\
\hline Average assay & 496.7 & 495.7 & 499.1 & 497.5 & 503.8 & 501.4 \\
\hline Label claimed & 500.0 & 500.0 & 500.0 & 500.0 & 500.0 & 500.0 \\
\hline Standard deviation (SD) & 6.4 & 7.0 & 5.6 & 4.8 & 5.1 & 7.9 \\
\hline $\begin{array}{l}\text { Coefficient of variation } \\
{[\mathrm{CV}, \%]}\end{array}$ & 1.27 & 1.40 & 1.12 & 0.96 & 1.01 & 1.58 \\
\hline
\end{tabular}

TLC-densitometric method compared with UV-spectrophotometric method

$t$-test

$\begin{array}{lccc}t \text { calculated } & 0.34 & 0.69 & 0.81 \\ t_{(95 \%, 18)} \text { tabulated } & 2.10 & 2.10 & 2.10 \\ \text { F-test } & & & 2.39 \\ F \text { calculated } & 1.24 & 1.36 & 3.18 \\ F_{(95 \%, f 1=f 2=9)} \text { tabulated } & 3.18 & 3.18 & \end{array}$

and UV-spectrophotometric methods, respectively. The coefficients of variance were smaller than $2 \%$ in each case. High reproducibility and insignificant differences between the two compared methods were obtained at the $95 \%$ probability level for $t$-test and $F$-test of significance of $0.34<2.10$ and 1.24 $<3.18 ; 0.69<2.10$ and $1.36<3.18 ; 0.81<2.10$ and $2.39<$ 3.18; respectively, for Product 1, Product 2, and Product 3. These results confirmed statistically that TLC-densitometric method is accurate and can be used as a substitute method.

Acetaminophen content in investigated pharmaceutical preparations is consistent with that reported by the Polish Pharmacopoeia [31]; acetaminophen content in the preparation should not be smaller than $95 \%$ and larger than the $105 \%$ of the declared value.

The results of this study and those presented in our previous papers [39-43] indicate that the validated TLCdensitometric method can be successfully applied to the determination of biological active compounds in selected pharmaceutical formulations.

\section{Conclusion}

Our TLC-densitometric study of acetaminophen indicates that of all applied chromatographic conditions, the most suitable are aluminium plates precoated with silica gel $60 \mathrm{~F}_{254}$ as stationary phase and a mixture of chloroform + acetone + ammonia (25\%) in volume compositions 8:2:0.1 as mobile phase. Above-mentioned chromatographic conditions resulted in optimum migration of acetaminophen and complete resolution of this compound from its related substances, namely, 4-aminophenol and $4^{\prime}$-chloroacetanilide from commercial products in combined dosage form. This fact confirmed the specificity of proposed method. According to the results of the experiments performed using the TLCdensitometric method, it was determined that the procedure used in this study is reliable with specificity, accuracy, precision, and robustness. The TLC-densitometric method also realizes the criterion of the linearity in the required range of acetaminophen concentrations. The results of validation of developed TLC-densitometric method for acetaminophen analysis indicate that the changes of the following chromatographic conditions such as sorbent type, the chamber type, extraction time, the temperature of plate activation, the distance of development, the wavelength, and the analyst used in our work can be successfully used as the new factors in robustness test of TLC-densitometric method, which is widely applied in drug analysis. 
Comparison of the acetaminophen content in tablets obtained from the TLC-densitometry to those determined by the use of the official UV-spectrophotometric method shows that acetaminophen content in investigated pharmaceutical preparations is consistent with that reported by the Polish Pharmacopoeia (is not smaller than 95\% and not larger than the $105 \%$ of the declared value). It could be said that the TLC-densitometric and UV-spectrophotometric methods mentioned in this study are suitable for the routine analysis of acetaminophen in quantity control laboratories. Moreover, the results in our work confirmed statistically that TLC-densitometric method is accurate and can be used as a substitute method for the accurate assay of the acetaminophen in pharmaceutical dosage forms, for example, in situation when UV-spectrophotometer or HPLC-UV is not affordable in laboratory.

\section{Disclosure}

The usage of this trade mark symbol or company name is for proving the genuineness of the work and not for any another purpose. The authors submitted this paper in a much elaborate manner by mentioning the trademarks or company names, in order to make each and every point or sentence clear or transparent. The authors of the paper do not have any financial relation with the commercial identity mentioned in their paper.

\section{Conflict of Interests}

The authors have no conflict of interests or no financial gains in mentioning the company names or trademarks.

\section{Acknowledgment}

This research was financed by the Medical University of Silesia as part of statutory research projects: KNW-1-004/P/1/0 and KNW-1-013/N/3/0.

\section{References}

[1] A. Wang, J. Sun, H. Feng, S. Gao, and Z. He, "Simultaneous determination of paracetamol and caffeine in human plasma by LC-ESI-MS," Chromatographia, vol. 67, no. 3-4, pp. 281-285, 2008.

[2] C. T. Archer and R. A. Richardson, "An improved colorimetric method for the determination of plasma paracetamol," Annals of Clinical Biochemistry, vol. 17, no. 1, pp. 45-46, 1980.

[3] A. Esteban, M. Graells, J. Satorre, and M. Pérez-Mateo, "Determination of paracetamol and its four major metabolites in mouse plasma by reversed-phase ion-pair high-performance liquid chromatography," Journal of Chromatography B, vol. 573, no. 1, pp. 121-126, 1992.

[4] O. Q. P. Yin, S. S. L. Lam, and M. S. S. Chow, "Simultaneous determination of paracetamol and dextropropoxyphene in human plasma by liquid chromatography/tandem mass spectrometry: application to clinical bioequivalence studies," Rapid Communications in Mass Spectrometry, vol. 19, no. 6, pp. 767-774, 2005.
[5] C. Celma, J. A. Allué, J. Pruñonosa, C. Peraire, and R. Obach, "Simultaneous determination of paracetamol and chlorpheniramine in human plasma by liquid chromatography-tandem mass spectrometry," Journal of Chromatography A, vol. 870, no. $1-2$, pp. 77-86, 2000.

[6] F. Shihana, D. Dissanayake, P. Dargan, and A. Dawson, "A modified low-cost colorimetric method for paracetamol (acetaminophen) measurement in plasma," Clinical Toxicology, vol. 48, no. 1, pp. 42-46, 2010.

[7] J. Parojcić, K. Karljiković-Rajić, Z. Durić, M. Jovanović, and S. Ibrić, "Development of the second-order derivative UV spectrophotometric method for direct determination of paracetamol in urine intended for biopharmaceutical characterisation of drug products," Biopharmarmaceutics and Drug Disposition, vol. 24, no. 7, pp. 309-314, 2003.

[8] R. Krishnamurthy, M. K. Malve, and B. M. Shinde, "Simultaneous determination of morphine, caffeine, and paracetamol in the urine of addicts by HPTLC and HPLC," Journal of Planar Chromatography-Modern TLC, vol. 13, no. 3, pp. 171-175, 2000.

[9] H. Filik, I. Şener, S. D. Cekiç, E. Kiliç, and R. Apak, "Spectrophotometric determination of paracetamol in urine with tetrahydroxycalix[4]arene as a coupling reagent and preconcentration with Triton X-114 using cloud point extraction," Chemical and Pharmaceutical Bulletin, vol. 54, no. 6, pp. 891-896, 2006.

[10] J. Meyer and U. Karst, "Determination of paracetamol (acetaminophen) by HPLC with post-column enzymatic derivatization and fluorescence detection," Chromatographia, vol. 54, no. 3-4, pp. 163-167, 2001.

[11] S. Heitmeier and G. Blaschke, "Direct determination of paracetamol and its metabolites in urine and serum by capillary electrophoresis with ultraviolet and mass spectrometric detection," Journal of Chromatography B, vol. 721, no. 1, pp. 93-108, 1999.

[12] I. Baranowska and A. Wilczek, "Simultaneous RP-HPLC determination of sotalol, metoprolol, $\alpha$-hydroxymetoprolol, paracetamol and its glucuronide and sulfate metabolites in human urine," Analytical Sciences, vol. 25, no. 6, pp. 769-772, 2009.

[13] A. Afkhami, N. Sarlak, and A. R. Zarei, "Spectrophotometric determination of salicylamide and paracetamol in biological samples and pharmaceutical formulations by a differential kinetic method," Acta Chimica Slovenica, vol. 53, no. 3, pp. 357$362,2006$.

[14] O. Fatibello-Filho, K. O. Lupetti, and I. C. Vieira, "Chronoamperometric determination of paracetamol using an avocado tissue (Persea americana) biosensor," Talanta, vol. 55, no. 4, pp. 685-692, 2001.

[15] M. A. Oliva, R. A. Olsina, and A. N. Masi, "Selective spectrofluorimetric method for paracetamol determination through coumarinic compound formation," Talanta, vol. 66, no. 1, pp. 229-235, 2005.

[16] S. D. Çekiç, H. Filik, and R. Apak, "Simultaneous spectrophotometric determination of paracetamol and $p$-aminophenol in pharmaceutical products with tiron using dissolved oxygen as oxidant," Journal of Analytical Chemistry, vol. 60, no. 11, pp. 1019-1023, 2005.

[17] K. Milenkova, A. Dimitrovska, L. Ugrinova, and S. TrajkovicJolevska, "Simultaneous determination of paracetamol, pseudoephedrine, hydrochloride and dextromethorphan hydrobromide in tablets by HPLC," Bulletin of Chemical Technology Macedonia, vol. 22, pp. 33-37, 2003. 
[18] U. D. Pawar, A. V. Naik, A. V. Sulebhavikar, T. A. Datar, and K. V. Mangaonkar, "Simultaneous determination of aceclofenac, paracetamol and chlorzoxazone by HPLC in tablet dose form," E-Journal of Chemistry, vol. 6, no. 1, pp. 289-294, 2009.

[19] S. Zhao, W. Bai, H. Yuan, and D. Xiao, "Detection of paracetamol by capillary electrophoresis with chemiluminescence detection," Analytica Chimica Acta, vol. 559, no. 2, pp. 195-199, 2006.

[20] D. Šatínský, I. Neto, P. Solich et al., "Sequential injection chromatographic determination of paracetamol, caffeine, and acetylsalicylic acid in pharmaceutical tablets," Journal of Separation Science, vol. 27, no. 7-8, pp. 529-536, 2004.

[21] L. Monser and F. Darghouth, "Simultaneous LC determination of paracetamol and related compounds in pharmaceutical formulations using a carbon-based column," Journal of Pharmaceutical and Biomedical Analysis, vol. 27, no. 6, pp. 851-860, 2002.

[22] H. E. Abdellatef, M. M. Ayad, S. M. Soliman, and N. F. Youssef, "Spectrophotometric and spectrodensitometric determination of paracetamol and drotaverine $\mathrm{HCl}$ in combination," Spectrochimica Acta A, vol. 66, no. 4-5, pp. 1147-1151, 2007.

[23] A. Dimitrovska, S. Trajkovic-Jolevska, A. Nancovska, and M. Ilievska, "Determination of propyphenazone, paracetamol, caffeine and codeine phosphate with thin layer chromatography," Bulletin of Chemical Technology Macedonia, vol. 14, pp. 39-41, 1995.

[24] H. Tavallali, S. F. Zareiyan, and M. Naghian, "An efficient and simultaneous analysis of caffeine and paracetamol in pharmaceutical formulations using TLC with a fluorescence plate reader," Journal of AOAC International, vol. 94, no. 4, pp. 1094-1099, 2011.

[25] C. Sullivan and J. Sherma, "Development and validation of an HPTLC-densitometry method for assay of caffeine and acetaminophen in multicomponent extra strength analgesic tablets," Journal of Liquid Chromatography and Related Technologies, vol. 26, no. 20, pp. 3453-3462, 2003.

[26] H. J. Shah, I. S. Rathod, S. A. Shah, S. S. Savale, and C. J. Shishoo, "Sensitive HPTLC method for monitoring dissolution profiles of diclofenac from different tablets containing combiined diclofenac and acetaminophen," Journal of Planar Chromatography-Modern TLC, vol. 16, no. 1, pp. 36-44, 2003.

[27] V. K. Mahajan, S. B. Bari, A. A. Shirkhedkar, and S. J. Surana, "Simultaneous densitometric TLC analysis of aceclofenac, paracetamol, and chlorzoxazone in tablets," Acta Chromatographica, vol. 20, no. 4, pp. 625-636, 2008.

[28] S. V. Gandhi, N. S. Barhate, B. R. Patel, D. D. Panchal, and K. G. Bothara, "A validated densitometric method for analysis of aceclofenac and paracetamol as the bulk drugs and in combined tablet dosage forms," Acta Chromatographica, vol. 20, no. 2, pp. 175-182, 2008.

[29] C. O'Sullivan and J. Sherma, "Model procedure for the transfer of TLC pharmaceutical product screening methods designed for use in developing countries to quantitative HPTLCdensitometry methods," Acta Chromatographica, vol. 24, no. 2, pp. 241-252, 2012.

[30] A. Yadav, R. M. Singh, S. C. Mathur, P. K. Saini, and G. N. Singh, "A simple and sensitive HPTLC method for simultaneous analysis of domperidone and paracetamol in tablet dosage forms," Journal of Planar Chromatography-Modern TLC, vol. 22, no. 6, pp. 421-424, 2009.
[31] Polish Pharmacopoeia, Polish Pharmaceutical Society, Warsaw, Poland, 2002.

[32] The United States Pharmacopoeia, Twinbrook Parkway, Rockville, Md, USA, 2011.

[33] ICH Harmonised Tripartite Guideline: Validation of Analytical Procedures: Text and Methodology, Q2(R1), ICH, Geneva, Switzerland, 2005, http://www.ich.org.

[34] K. Ferenczi-Fodor, B. Renger, and Z. Végh, "The frustrated reviewer-recurrent failures in manuscripts describing validation of quantitative TLC/HPTLC procedures for analysis of pharmaceuticals," Journal of Planar Chromatography-Modern TLC, vol. 23, no. 3, pp. 173-179, 2010.

[35] K. Ferenczi-Fodor, A. Nagy-Turák, and Z. Végh, "Validation and monitoring of quantitative thin layer chromatographic purity tests for bulk drug substances," Journal of Planar Chromatography-Modern TLC, vol. 8, no. 5, pp. 349-356, 1995.

[36] A. Pyka, M. Budzisz, and M. Dołowy, "Zastosowanie TLC i densytometrii do ilościowego oznaczania paracetamolu w wybranych preparatach farmaceutycznych," in Chromatografia w Praktyce, A. Voelkel and W. Wasiak, Eds., pp. 137-147, Wydawnictwo Politechniki Poznańskiej, 2011.

[37] A. Nagy-Turák, Z. Végh, and K. Ferenczi-Fodor, "Validation of the quantitative planar chromatographic analysis of drug substances. III. Robustness testing in OPLC," Journal of Planar Chromatography-Modern TLC, vol. 8, no. 3, pp. 188-193, 1995.

[38] C. D. Hendix, "What every technologist should know about experiment design," Chemical Technology, vol. 9, pp. 167-174, 1979.

[39] A. Pyka, E. Wiatr, K. Kwiska, and D. Gurak, "Validation thin layer chromatography for the determination of naproxen in tablets and comparison with a pharmacopeil method," Journal of Liquid Chromatography and Related Technologies, vol. 34, no. 10-11, pp. 829-847, 2011.

[40] A. Pyka, D. Nabiałkowska, K. Bober, and M. Dołowy, "Comparison of NP-TLC and RP-TLC with densitometry to quantitative analysis of tocopherol acetate in pharmaceutical preparation," Journal of Liquid Chromatography and Related Technologies, vol. 34, no. 20, pp. 2548-2564, 2011.

[41] A. Pyka, M. Babuśka-Roczniak, and P. Bocheńska, "Determination of hydrocortisone in pharmaceutical drug by TLC with densitometric detection in UV," Journal of Liquid Chromatography and Related Technologies, vol. 34, no. 9, pp. 753-769, 2011.

[42] P. Bocheńska and A. Pyka, "Determination of acetylsalicylic acid in pharmaceutical drugs by TLC with densitometric detection in UV," Journal of Liquid Chromatography and Related Technology, vol. 35, pp. 1346-1363, 2012.

[43] P. Bocheńska and A. Pyka, "Use of TLC for the quantitative determination of acetylsalicylic acid, caffeine, and ethoxybenzamide in combined tablets," Journal of Liquid Chromatography and Related Technology, vol. 36, pp. 2405-2421, 2013. 

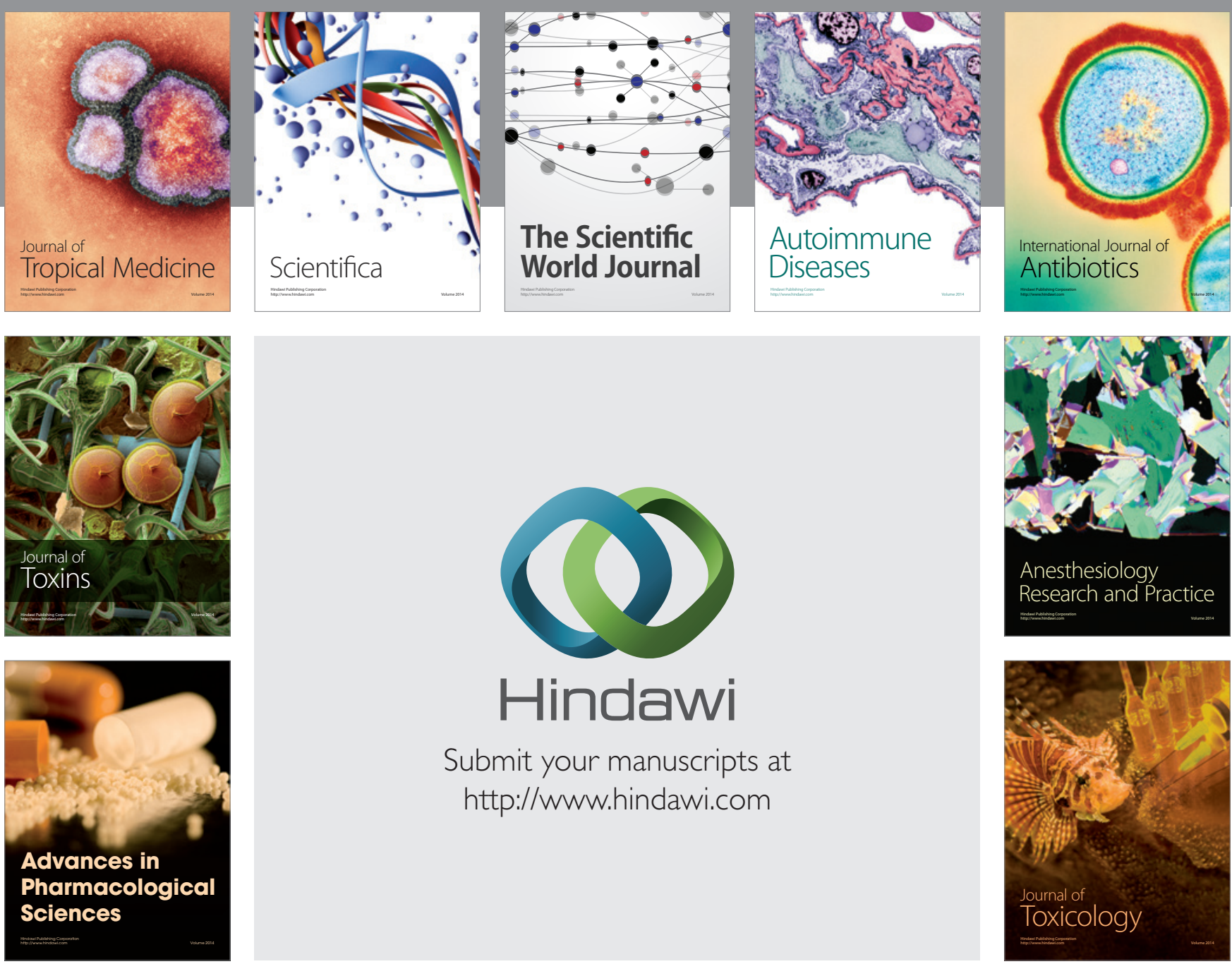

\section{Hindawi}

Submit your manuscripts at

http://www.hindawi.com
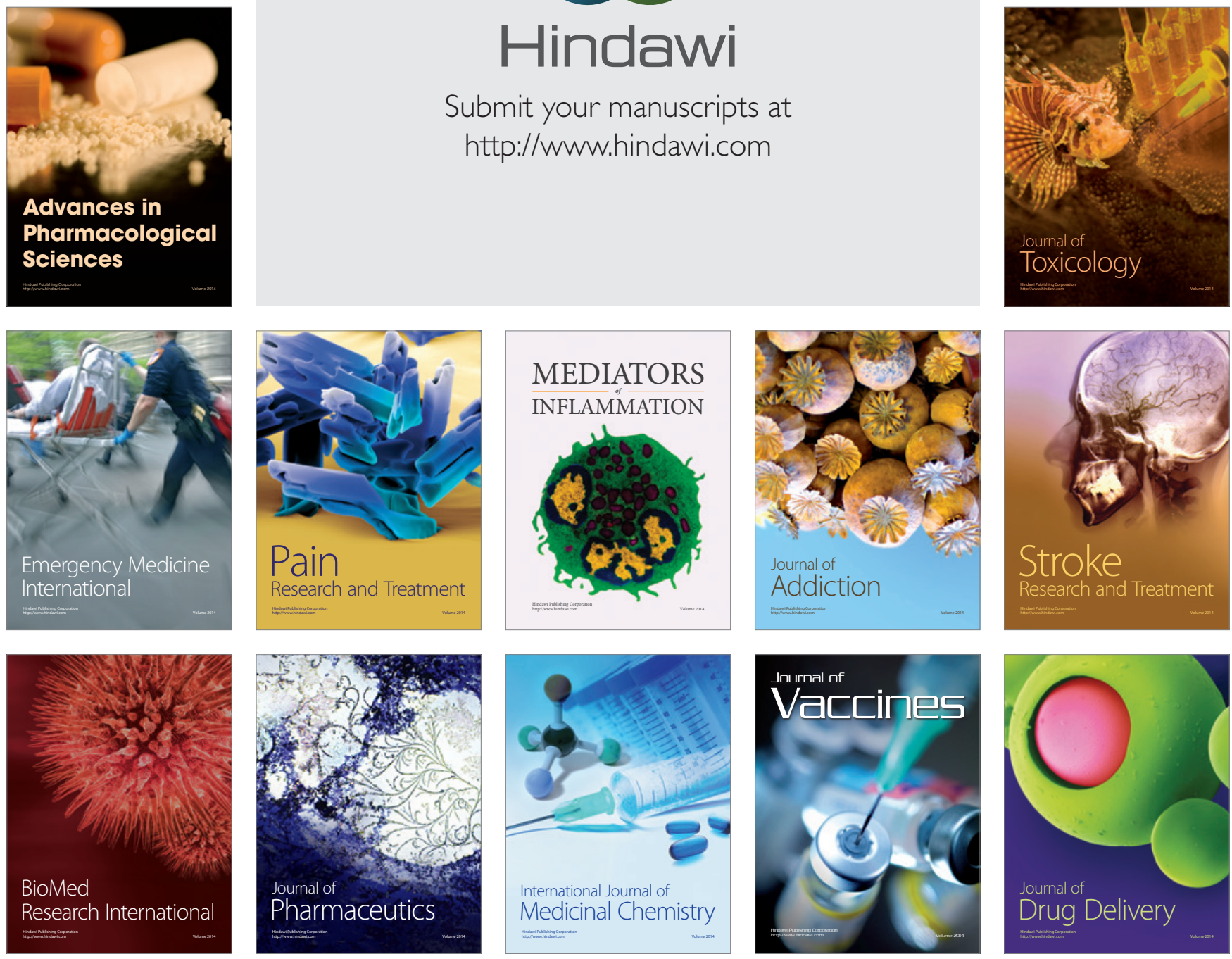